\title{
Improvement of hydrothermal stability of MCM-41 mesoporous molecular sieve
}

\author{
Debasish Das, Chou-Mei Tsai and Soofin Cheng* \\ Department of Chemistry, National Taiwan University, Taipei 106, Taiwan.E-mail: chem1031@ccms.ntu.edu.tw
}

Received (in Cambridge, UK) 17th December 1998, Accepted 25th January 1999

\begin{abstract}
Addition of cations such as tetraalkylammonium or sodium ions to the synthesis gel results in considerable improvement of the hydrothermal stability of mesoporous molecular sieve MCM-41.
\end{abstract}

The recent development of the mesoporous molecular sieve MCM-41 by the workers of Mobil ${ }^{1,2}$ has attracted much attention because of the potential of these materials for use as catalysts or catalyst supports. The structure of MCM-41 consists of a hexagonal array of one-dimensional channels of uniform mesopores with pore diameter in the range 15-100 $\AA$, depending on the nature of the template and synthesis conditions. The presence of these very large uniform pores opens up the possibilities for shape-selective conversions of bulky molecules such as those encountered in the manufacture of fine chemicals and pharmaceuticals. ${ }^{3}$

The main drawback of MCM-41 molecular sieve for practical applications is its rather low hydrothermal stability. The hexagonal arranged silica framework is stable when surfactant template molecules are present. However, the calcined samples, which have no templates in the pores, have very poor structural stability, especially in hot water. By contrast, the crystal structure of pure silica MCM-41 was found to be retained up to $850{ }^{\circ} \mathrm{C}^{4}$ or in a $100 \%$ steam flow under atmospheric pressure at $500{ }^{\circ} \mathrm{C} .{ }^{5}$ Nevertheless, the structure of MCM-41 collapses if it is placed in hot water or aqueous solution for an extended period of time. Partial substitution of Si by other atoms like Ti or $\mathrm{Al}$ was reported to improve the thermal and hydrothermal stability to some extent. ${ }^{6}$ It was also reported that improved hydrothermal stability could be achieved by adjusting the gel $\mathrm{pH}$ several times during the hydrothermal crystallization process. ${ }^{7}$ However, this $\mathrm{pH}$ adjustment is a tedious process and the high pressure crystallization reaction has to be interrupted repeatedly. Here, we report that significant improvement in the hydrothermal stability of MCM-41 can be achieved by simply adding different tetraalkylammonium $\left(\mathrm{TAA}^{+}\right)$or sodium ions to the synthesis gel and without the necessity of multiple $\mathrm{pH}$ adjustment steps.

The hydrothermal crystallization procedure described earlier ${ }^{8}$ was slightly modified to obtain MCM-41 samples. The synthesis gel was prepared by adding sodium silicate solution (ca. 3.7\% NaOH, ca. $7.0 \% \mathrm{SiO}_{2}$ ), to a clear solution containing cetyltrimethylammonium bromide $(\mathrm{CTMABr}, 99+\%)$ and tetraalkylammonium $\left(\mathrm{TAA}^{+}\right)$or sodium bromide salts. After stirring the mixture for $c a$. $10 \mathrm{~min}$ at room temp., a measured amount of $1.10 \mathrm{M}$ sulfuric acid (p.a. grade) was added to the gel and the $\mathrm{pH}$ value was adjusted to $c a$. 9.5-10. The molar ratio of the final gel composition is $\mathrm{SiO}_{2}: 0.48 \mathrm{CTMA}^{+}:(0-0.96) \mathrm{TAA}^{+}$: $0.39 \mathrm{Na}_{2} \mathrm{O}: 0.29 \mathrm{H}_{2} \mathrm{SO}_{4}: 50-110 \mathrm{H}_{2} \mathrm{O}$. The gel mixture was stirred for $2 \mathrm{~h}$ at room temp. and then transferred into polypropylene bottles and statically heated at $100{ }^{\circ} \mathrm{C}$ for 4 days under autogenerated pressure. The final solid material obtained was filtered off, washed until free of $\mathrm{Br}^{-}$ions, dried and calcined at $560{ }^{\circ} \mathrm{C}$.

The hydrothermal stability of the synthesized samples was investigated by mixing $c a$. $0.2 \mathrm{~g}$ of the calcined sample with 20 $\mathrm{g}$ deionised water and heating in a closed bottle at $100{ }^{\circ} \mathrm{C}$ under static conditions for different time periods. After hydrothermal treatment, the samples were filtered, washed with deionised water and dried at $70{ }^{\circ} \mathrm{C}$ overnight. The hydrothermal stability was monitored by following the peak intensities of the X-ray diffraction patterns recorded on a Scintag X1 diffractometer using $\mathrm{Cu}-\mathrm{K} \alpha$ radiation $(\lambda=0.154 \mathrm{~nm})$. Nitrogen adsorption/ desorption isotherms at liquid $\mathrm{N}_{2}$ temperature were measured using a Micromeritics ASAP 2100 system. Prior to the experiments, samples were outgassed at $300{ }^{\circ} \mathrm{C}$ for $c a .6-8 \mathrm{~h}$ under vacuum $\left(10^{-3}\right.$ Torr). Mesopore size distribution was calculated from the desorption branch of the isotherm by the BJH (Barrett-Joyner-Halenda) method using the Halsey equation. ${ }^{29} \mathrm{Si}$ MAS NMR spectra were acquired at $59.62 \mathrm{MHz}$ with $30^{\circ}$ pulse duration of $2.0 \mathrm{~ms}, 60 \mathrm{~s}$ recycle delay using a Bruker MSL-300 spectrometer.

The effect of added $\mathrm{TAA}^{+}$cation concentration was studied by using tetrapropylammonium cation. It was found that with $\mathrm{TPA}^{+} /$surfactant molar ratios up to 2.0, the MCM-41 structure could be obtained. Further increase in $\mathrm{TPA}^{+}$concentration results in either poorly crystalline or amorphous material Highly ordered MCM-41 samples were obtained at $\mathrm{TPA}^{+} /$ surfactant ratios of 0.6-1.4. XRD patterns of the samples showed a very intense (100) diffraction peak and three additional higher order peaks with lower intensities. This suggests that these samples have a high degree of long range ordering of the structure and well formed hexagonal pore arrays. The specific surface area, $A_{\mathrm{BET}}$, as determined from the linear part of the BET equation $\left(p / p_{\mathrm{o}}=0.05-0.3\right)$, shows that these samples have a very high surface area of $c a .1000 \mathrm{~m}^{2} \mathrm{~g}^{-1}$. All the samples show typical type IV adsorption isotherms of cylindrical mesopores with a sharp inflection at $p / p_{0} \approx 0.3$. Pore size distribution curves show a remarkably narrow pore size distribution with a pore size of $c a .27 \AA$. The pore wall thickness as estimated from the difference of the X-ray unit cell parameter $\left(a_{\mathrm{o}}\right)$ and the peak pore diameter was found to be $c a$. 18-19 $\AA$ for the calcined samples.

The XRD patterns of the water-treated samples show that all the samples synthesized with the addition of $\mathrm{TPA}^{+}$are quite stable to hydrothermal treatment at $100{ }^{\circ} \mathrm{C}$ for 4 days. The intensity of the (100) peak remains very strong although the other higher order peaks become smaller. The slight shift of the (100) peak position towards higher $2 \theta$ values indicates the contraction of the pores due to an increase in pore wall thickness.

The effect of addition of cations other than TPA ${ }^{+}$is shown in Fig. 1 and the physical properties of the MCM-41 samples prepared with different cations are also listed in Table 1. A cation/surfactant molar ratio of 1.4 was used in the synthesis. It can be seen that highly ordered MCM-41 materials were also obtained with $\mathrm{TMA}^{+}$, TEA ${ }^{+}$and even $\mathrm{Na}^{+}$ions. The BET surface areas, $A_{\mathrm{BET}}$, of these samples are in the range $1010-1070 \mathrm{~m}^{2} \mathrm{~g}^{-1}$. Mesopore size distribution analysis showed a very narrow distribution with a peak pore diameter of $c a .27$ A. By contrast, earlier workers reported that without any $\mathrm{pH}$ adjustment steps, addition of salts like sodium chloride resulted in poorly ordered MCM-41 samples. ${ }^{7}$

The MCM-41 crystalline structures were well retained after hydrothermal treatment of the calcined samples at $100{ }^{\circ} \mathrm{C}$ for 4 days (Fig. 1). Only slight decreases of the (100) peak intensity and the long-range structural ordering were observed. The surface area and pore volume of the water-treated samples were 
Table 1 Physical properties of MCM-41 samples prepared with different additional cations

\begin{tabular}{|c|c|c|c|c|c|c|c|}
\hline \multirow[b]{2}{*}{ Cation } & \multirow[b]{2}{*}{ Treatment } & \multirow{2}{*}{$\begin{array}{l}A_{\mathrm{BET}} / \\
\mathrm{m}^{2} \mathrm{~g}^{-1}\end{array}$} & \multicolumn{3}{|l|}{ Mesopores } & \multirow{2}{*}{$\begin{array}{l}\text { Peak pore } \\
\text { diameter/A }\end{array}$} & \multirow{2}{*}{$\begin{array}{l}\text { Wall } \\
\text { thickness/A }\end{array}$} \\
\hline & & & $A_{\mathrm{BJH}} / \mathrm{m}^{2} \mathrm{~g}^{-1}$ & $V_{\mathrm{BJH}} / \mathrm{cm}^{3} \mathrm{~g}^{-1}$ & $D_{\mathrm{BJH}} / \AA$ & & \\
\hline \multirow[t]{2}{*}{$\mathrm{TPA}^{+}$} & Calcined & 1030 & 1126 & 0.76 & 27.0 & 27.0 & 17.2 \\
\hline & Water-treated & 1030 & 1053 & 0.70 & 26.6 & 24.0 & 20.6 \\
\hline \multirow[t]{2}{*}{$\mathrm{TEA}^{+}$} & Calcined & 1010 & 1155 & 0.80 & 27.7 & 27.0 & 18.5 \\
\hline & Water-treated & 940 & 1130 & 0.76 & 26.9 & 24.2 & 21.2 \\
\hline \multirow[t]{2}{*}{$\mathrm{TMA}^{+}$} & Calcined & 1045 & 1234 & 0.87 & 28.2 & 27.0 & 19.4 \\
\hline & Water-treated & 960 & 1175 & 0.79 & 26.9 & 24.2 & 20.6 \\
\hline \multirow[t]{2}{*}{$\mathrm{Na}^{+}$} & Calcined & 1020 & 1159 & 0.80 & 27.6 & 27.1 & 17.9 \\
\hline & Water-treated & 920 & 1079 & 0.72 & 26.7 & 24.1 & 19.2 \\
\hline \multirow[t]{2}{*}{-} & Calcined & 1070 & 1216 & 0.83 & 27.3 & 26.8 & 19.3 \\
\hline & Water-treated & 705 & 369 & 0.23 & 24.9 & $\simeq^{a}$ & $-a$ \\
\hline
\end{tabular}

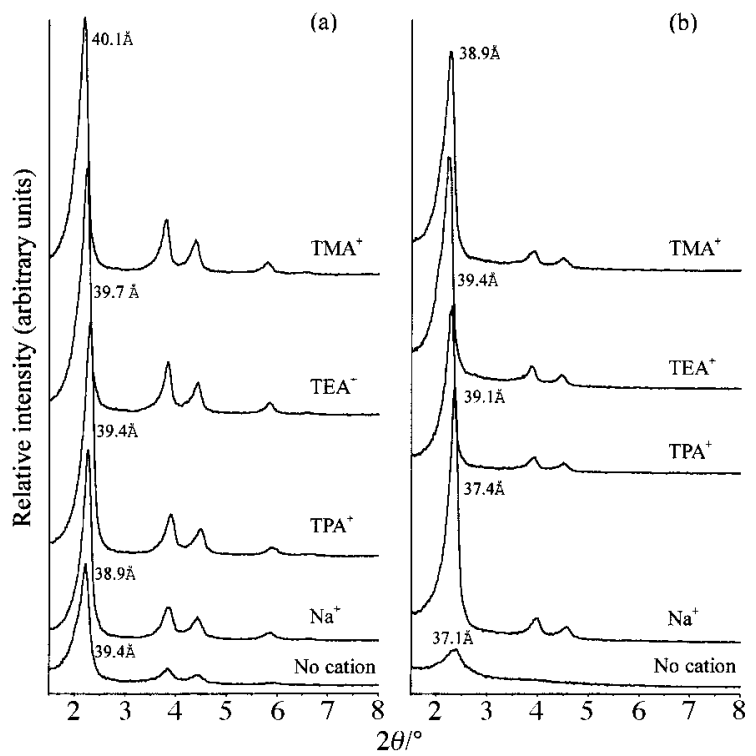

Fig. 1 XRD patterns of the MCM-41 samples prepared with the addition of different cations; (a) calcined samples and (b) after hydrothermal treatment at $100{ }^{\circ} \mathrm{C}$ for 4 days.

slightly lower than those of the calcined samples. From the nature of the adsorption isotherms and the pore size distribution curves, the pore size distribution was slightly broadened for $\mathrm{TAA}^{+}$and $\mathrm{Na}^{+}$modified samples after water treatment, but the mesoporous structure was unaltered. Also, the peak pore diameter shifts slightly towards lower values due to increased pore wall thickness. By contrast, for a sample prepared without addition of $\mathrm{TAA}^{+}$or extra $\mathrm{Na}^{+}$ions, the hexagonal pattern almost disappeared after hydrothermal treatment. The mesopore area of the unmodified sample decreases drastically after hydrothermal treatment, indicating severe disintegration of the mesostructure. It is also noted here that samples prepared without additional cations have similar pore wall thickness to those prepared by adding different cations. Hence, the increased hydrothermal stability is not related to the pore wall thickness as reported earlier. ${ }^{9}$

It appears that during the formation of the surfactant-silicate mesostructure, the electrostatic interaction between the cationic surfactant micelles and the surrounding silicate anions is altered by the presence of the additional cations. ${ }^{29} \mathrm{Si}$ MAS NMR spectra of the samples prepared with and without $\mathrm{TPA}^{+}$are shown in Fig. 2. It can be seen that the $\mathrm{Q}_{4} / \mathrm{Q}_{3}$ ratio in the assynthesized samples was much higher for that prepared in the presence of $\mathrm{TPA}^{+}$. The higher $\mathrm{Q}_{4} / \mathrm{Q}_{3}$ ratio indicates that there is increased condensation between the silanol groups during the formation of the mesostructure.

These results suggest that MCM-41 type mesoporous materials with a high degree of hydrothermal stability can be

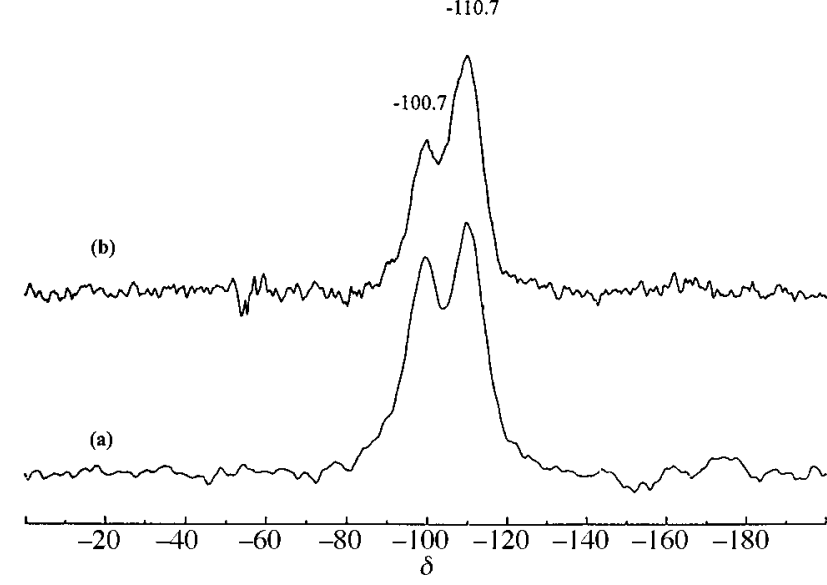

Fig. $2{ }^{29}$ Si MAS NMR spectra of MCM-41 samples prepared (a) without additional cations and (b) with $\mathrm{TPA}^{+}$ions.

directly obtained without tedious $\mathrm{pH}$ adjustment steps by adding additional cations in the synthesis gel. Although the exact roles of these additional cations are still not clear, their presence seems to facilitate increased condensation of the silanol groups during the formation of the mesostructure. The highly condensed silica wall is considered to have better structural stability under hydrothermal treatment conditions.

Financial support from the China Petroleum Corporation, Taiwan is gratefully acknowledged. One of the authors (D. D.) thanks the National Science Council, Taiwan for a post-doctoral fellowship.

\section{Notes and references}

1 C. T. Kresge, M. E. Leonowicz, W. J. Roth, J. C. Vartuli and J. S. Beck, Nature, 1992, 359, 710.

2 J. S. Beck, J. C. Vartuli, W. J. Roth, M. E. Leonowicz, C. T. Kresge, K. D. Schmitt, C. T. W. Chu, D. H. Olson, E. W. Sheppard, S. B. McCullen, J. B. Higgins and J. L. Schlenker, J. Am. Chem. Soc., 1992, 114, 10834.

3 A. Corma, V. Fornés, M. T. Navarro and J. Pérez-Pariente, J. Catal., 1994, 148, 569

4 C. Y. Chen, H. X. Li and M. E. Davis, Microporous Mater., 1993, 2, 17.

5 J. M. Kim, J. H. Kwak, S. Jun and R. Ryoo, J. Phys. Chem., 1995, 99, 16742.

6 L. Y. Chen, S. Janicke and G. K. Chuah, Microporous Mater., 1997, 12, 323.

7 R. Ryoo and S. Jun, J. Phys. Chem., 1997, 101, 317.

8 H. P. Lin, C. Y. Mou and S. Cheng, Microporous. Mater., 1997, 10, 111

9 N. Coustel, F. Di Renzo and F. Fajula, J. Chem. Soc., Chem. Commun., 1994, 967.

Communication 8/09815H 